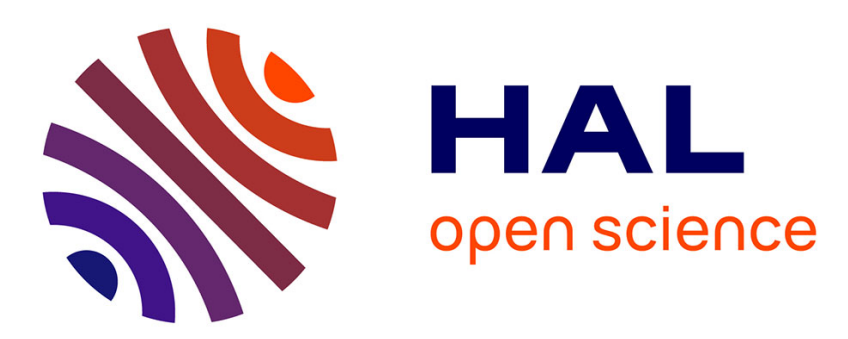

\title{
The effects of strain rate, temperature and constraint on the large scale yielding fracture initiation behaviour of a mining steel
}

\author{
R. Mines, S. Mcparland
}

\section{- To cite this version:}

R. Mines, S. Mcparland. The effects of strain rate, temperature and constraint on the large scale yielding fracture initiation behaviour of a mining steel. Journal de Physique IV Proceedings, 1994, 04 (C8), pp.C8-753-C8-758. 10.1051/jp4:19948116 . jpa-00253358

\section{HAL Id: jpa-00253358 https://hal.science/jpa-00253358}

Submitted on 1 Jan 1994

HAL is a multi-disciplinary open access archive for the deposit and dissemination of scientific research documents, whether they are published or not. The documents may come from teaching and research institutions in France or abroad, or from public or private research centers.
L'archive ouverte pluridisciplinaire HAL, est destinée au dépôt et à la diffusion de documents scientifiques de niveau recherche, publiés ou non, émanant des établissements d'enseignement et de recherche français ou étrangers, des laboratoires publics ou privés. 


\title{
The effects of strain rate, temperature and constraint on the large scale yielding fracture initiation behaviour of a mining steel
}

\author{
R.A.W. Mines and S. McParland \\ University of Liverpool, U.K.
}

\begin{abstract}
Résumé: L'article décrit le mesurage de la résistance dans les conditions de fracture dynamique d'un acier minier. Les conditions de température, du taux de tension et de la constrainte sur le choix du matériel étaient variées. On s'est serui des modèles théoretiques qui existent déjà pour faire l'étude des relations entre les propriétés micro-structurales matérielles et les valeurs mesurées de la résistance.
\end{abstract}

\begin{abstract}
The paper describes the measurement of the dynamic fracture toughness of a mining steel. The conditions of temperature,strain rate and material constraint were varied. Existing theoretical models were used to study the relation between microstructural material properties and measured values of toughness.
\end{abstract}

\section{INTRODUCTION}

The variation in the dynamic initiation fracture toughness of steels has been measured by Krabiell and Dahl using compact tension specimens loaded in a high rate servohydraulic machine [1]. Their results showed a reduction in fracture toughness with strain rate. Klepaczko [2] modelled this trend by assuming a HRR singularity at the crack tip and by using the criterion for cleavage fracture as a critical stress being exceeded over a specific microstructural distance. Klepaczko also considered the case of ductile fracture, in which the crack tip blunts, the HRR singularity is lost and the criterion for fracture becomes a critical strain being exceeded over a specific microstructural distance.

In the above it is assumed that small scale yielding conditions exist, i.e. fracture can be characterised by the Plane Strain Fracture Toughness, $\mathrm{K}_{\mathrm{Ic}}$. For small ligament sizes and ductile metals, $\mathrm{K}$ dominance is lost. Fracture under large scale yielding can be described in terms of the J integral [3]. The measurement of dynamic $J_{\text {Ic }}$ properties has not been discussed extensively in the literature. This paper concerns the measurement of dynamic $\mathrm{J}_{\mathrm{Ic}}$ properties using CT and Charpy specimens. It is assumed that fracture occurs under plane strain conditions, this giving maximum constraint and hence the greatest possibility of cleavage fracture.

\section{EXPERIMENTAL}

The material selected for study was a mining steel (BS2772:150M12). The material had the following composition: $0.15 \% \mathrm{C}, 0.21 \% \mathrm{Si}, 1.5 \% \mathrm{Mn}, 0.029 \% \mathrm{P}, 0.038 \% \mathrm{~S}, 0.020 \% \mathrm{Cr}, 0.04 \% \mathrm{Mo}$, $0.05 \% \mathrm{Ni}$ and $0.02 \% \mathrm{Cu}$. This material had previously been studied under static conditions [4]. Given the large strain rate and temperature range to be studied, two experimental techniques were used - namely the Hopkinson Pressure Bar loaded Instrumented Charpy Test and Compact Tension Specimens loaded in an ESH high rate servohydraulic machine. Two CT specimen widths were tested, namely 5 and $10 \mathrm{~mm}$ whereas only one Charpy specimen width was tested, namely $10 \mathrm{~mm}$. The material was provided in the form of $32 \mathrm{~mm}$ thick rolled plate. The specimens were machined so that the fracture plane was across the 
rolling direction. Fracture specimens were fatigue pre-cracked in an Amsler vibrophore. Dynamic tensile tests were also conducted in the high rate servohydraulic machine.

The HPB instrumented Charpy test has been described in reference [5]. For the low temperature tests the fatigue precracked Charpy specimen was cooled in liquid nitrogen, and then was placed on the impact rig and tested when thermocouple readings attained required values. This testing technique has been validated [6]. In the case of the compact tension and tensile tests in the high rate servohydraulic machine the liquid nitrogen bath was removed and the specimen allowed to heat up to the testing temperature. Again specimen temperature was measured using thermocouples attached to the specimens. In the case of the compact tension specimens the crack opening displacement in line with the loading pins was measured using a Zimmer electro-optical extensometer. The Zimmer was focussed on edges X in figure 1. A piezoelectric load cell was sited as near to the CT specimen as possible for load measurement. In the case of the tensile tests, specimen load was measured from an elastic gauge length and large strains were measured using the Zimmer. The tensile specimen geometry and experimental procedure is described in reference [7]

Transient signals were amplified using $1 \mathrm{MHz}$ Tektronix Differential Amplifiers and stored on Datalab DL1080 20MHz Transient Recorders. Signals were then transferred to a BBC Archimides microcomputer and traces digitally filtered and manipulated to give force $\mathrm{v}$ displacement and stress $\mathrm{v}$ strain data using inhouse software.

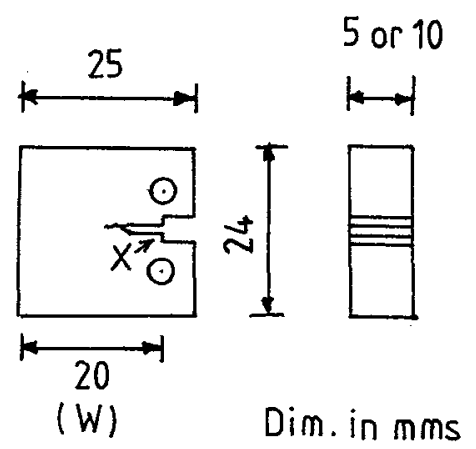

Figure 1: Compact Tension Specimen (to ASTM standard[8]). The electro-optical extensometer was focussed on edges $\mathrm{X}$ for COD measurement.

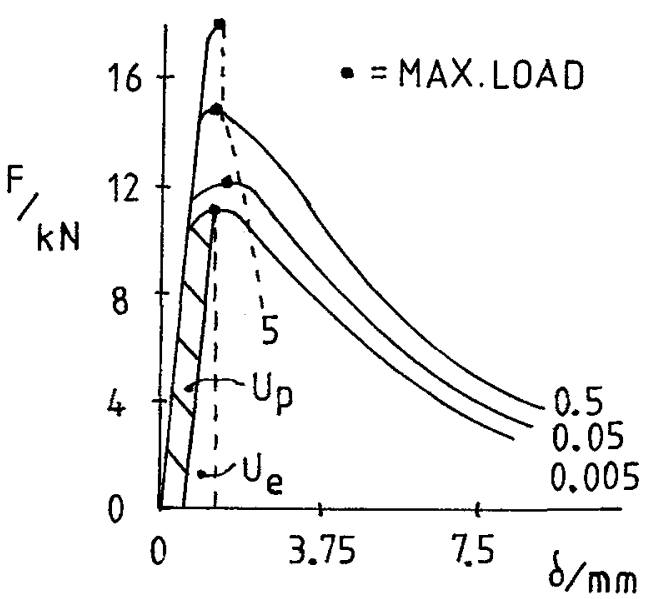

Figure 2: Load displacement data for $10 \mathrm{~mm}$ thick CT specimen at $\mathrm{T}=-20^{\circ} \mathrm{C}$ and at crosshead speeds of $0.005,0.05,0.5$, and $5 \mathrm{~ms}^{-1}$.

\section{DATA REDUCTION}

[8]:-

Before applying the $\mathrm{J}$ integral, the conditions for $\mathrm{J}$ dominance need to be defined. For static loading

$$
\mathrm{B}, \mathrm{W}-\mathrm{a} \geq 25\left(\frac{\mathrm{J}_{\mathrm{Ic}}}{\sigma_{\mathrm{y}}}\right)
$$

where $B$ is the width of the specimen, $W$-a is the ligament size and $\sigma_{y}$ is the yield stress. For dynamic loading $\mathrm{J}_{\mathrm{Ic}}$ reduces and $\sigma_{\mathrm{y}}$ increases so the right hand side of equation (1) reduces. For the static material properties, at room temperature, of the mining steel considered here, the right hand side of equation (1) equals $8 \mathrm{~mm}$. Hence the $5 \mathrm{~mm}$ thickness CT specimens and the Charpy specimens are slightly outside this criterion for static conditions.

In the case of the Charpy tests only small scale yielding conditions could be analysed given the limited loading time of the Hopkinson Pressure Bar apparatus [5]. However given the fact that the bulk of fracture tests for the mining steel were conducted under large scale yielding conditions all results are expressed in terms of the $J$ integral. Hence for the Charpy test:-

$$
\mathrm{J}_{\mathrm{Id}}=\frac{2 \mathrm{U}_{\mathrm{f}}}{\mathrm{B}(\mathrm{W}-\mathrm{a})}
$$

where $U_{f}$ is the area under the force displacement curve, $B$ is the specimen thickness and $W-a$ is the 
ligament size. The point of crack initiation was measured by a crack tip strain gauge and contact stiffness effects did not have to be taken into account [5].

The data reduction procedures for dynamic elasto-plastic compact tension specimen tests were taken from reference [9]. In this case elastic energy $\left(U_{e}\right)$ and plastic energy $\left(U_{p}\right)$ up to fracture were measured as shown in figure 2. The main problem is to define the point of crack initiation. In the transition region, stable cracking can occur prior to maximum load and hence dynamic $R$ curves are a more accurate approach [10]. However given the large strain rate and temperature range covered in these tests, it was decided to accept the more approximate maximum load at failure. Hence:-

$$
J_{I m}=\left[\frac{P_{m}}{B \sqrt{W}} f\left(\frac{a_{o}}{W}\right)\right]^{2} \frac{\left(1-v^{2}\right)}{E}+\frac{\eta_{p} U_{p}}{B\left(W-a_{o}\right)}
$$

where $P_{m}$ is the maximum load, $W$ is given in figure $1, a_{0}$ is the crack length and $\eta_{p}$ is given by :-

$$
\eta_{\mathrm{p}}=2+0.522\left(1-\frac{\mathrm{a}_{0}}{\mathrm{~W}}\right)
$$

and $\mathrm{f}\left(\mathrm{a}_{\mathrm{o}} / \mathrm{W}\right)$ is an elastic calibration function.

In both types of fracture test the crack tip strain rate is approximated by:-

$\dot{\mathrm{J}}=\frac{\mathrm{J}_{\mathrm{Im}}}{\mathbf{t}_{\mathrm{f}}}$

where $t_{f}$ is the time to fracture.Care is required here in that if the specimen force $v$ displacement characteristic is flat at the time of fracture then the instantaneous $\hat{\mathbf{J}}$ is markedly different from the averaged values. This effect was neglected in this work.

The data reduction technique for the tensile tests is discussed in reference [7].

\section{EXPERIMENTAL RESULTS AND DISCUSSION}

Figure 2 gives typical force - displacement curves for the compact tension specimen tests. Note the fracture transition from crosshead speed 0.5 to $5 \mathrm{~ms}^{-1}$. The points of crack initiation, at maximum load, are shown. The complete toughness results for the $10 \mathrm{~mm}$ thick tests are shown in figure 3 . The experimental data indicate trends in fracture toughness as shown by the dotted lines. In other words the effect of strain rate is to delay transition to the upper shelf. On the upper shelf the effect of strain rate is to increase fracture toughness. Figure 4 shows data plotted as a function of strain rate showing a reduction in fracture toughness with rate at low temperatures and an increase in toughness at high temperatures. Test results in figures 3 and 4 that have been derived from Charpy tests are annotated with a letter ' $C$ '. Only single Charpy results are shown at each temperature, for clarity. A large number of repeat tests showed consistent data. The Charpy test could not be used for large scale plasticity. Also the CTS tests gave inaccurate results for low temperatures and high rates e.g. $\mathrm{T}=-20^{\circ} \mathrm{C}$ and $\mathrm{V}=5 \mathrm{~ms}^{-1}$ in figure 2 . The latter is attributed to crack initiation before maximum load. Figure 5 compares $10 \mathrm{~mm}$ with $5 \mathrm{~mm}$ specimen thickness data. The smaller thickness reduces material constraint and hence there is no transition from upper to lower shelf behaviour due to strain rate. Larger scatter occurred for the small specimen thickness due to the lower overall specimen energies.

The measured dynamic tensile data was expressed in terms of Cowper Symonds constants, i.e. D $=3075 \mathrm{~s}^{-1} \mathrm{q}=8.2$ at room temperature, where:-

$$
\frac{\sigma_{\text {yd }}}{\sigma_{\text {ys }}}=\left(1+\left(\frac{\dot{\varepsilon}}{D}\right)^{\frac{1}{q}}\right)
$$

where $\dot{\varepsilon}$ is the uniaxial strain rate.From the tensile experimental tests it was shown that $D$ and $q$ were approximately temperature independent. Also the work hardening (n) was approximately rate independent for this material for the strain rate studied. The work hardening index was measured by curve fitting experimental data to the power law hardening model:

$$
\left(\frac{\varepsilon}{\varepsilon_{\mathrm{y}}}\right)=\alpha\left(\frac{\sigma}{\sigma_{\mathrm{y}}}\right)^{\mathrm{n}}
$$

and for static conditions and room temperature $\sigma_{\mathrm{y}}=405 \times 10^{6} \mathrm{~Pa}, \varepsilon_{\mathrm{y}}=0.0024, \mathrm{n}=8$ and $\alpha=8.4$. It is assumed that $\alpha$ is a constant and also, for this material $\mathrm{n}$ did not change markedly with temperature. The yield stress for the steel under static conditions was relatively constant up to $-10^{\circ} \mathrm{C}$ and then increased to $531 \times 10^{6} \mathrm{~Pa}$ at $-40^{\circ} \mathrm{C}$. In other words, the main temperature and rate effects occur in $\sigma_{\mathrm{y}}$. 


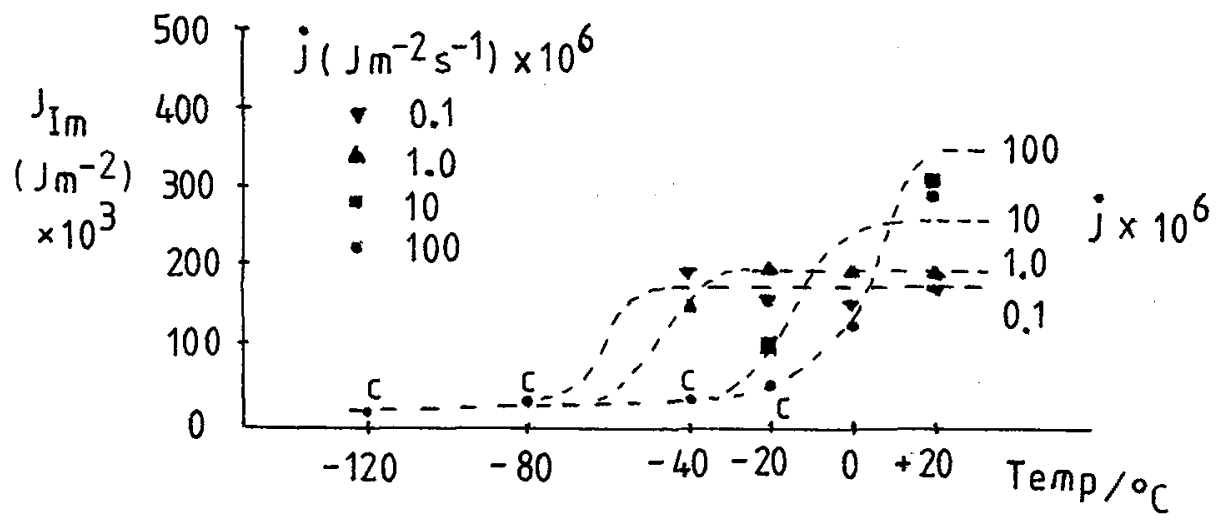

Figure 3: $\mathrm{J}_{\mathrm{Im}}$ versus temperature data for various strain rates $(\mathrm{J})$ for $10 \mathrm{~mm}$ wide Charpy and Compact Tension specimens. Annotation ' $C$ ' denotes a Charpy test result.

\section{THEORETICAL MODELLING OF RATE DEPENDENCE OF FRACTURE TOUGHNESS}

In order to gain insight into the effect of rate dependence of material properties the analysis due to Klepaczko [2] (see introduction) has been adapted for the large scale yielding case. In other words the value of $\mathrm{J}_{\mathrm{Ic}}$ for brittle fracture is predicted by:-

$$
\mathrm{J}_{\mathrm{Ic}}=\frac{\mathrm{I}_{\mathrm{n}}}{[\mathrm{f}(\mathrm{n})]^{\mathrm{n}+1}} \alpha \varepsilon_{\mathrm{y}} \sigma_{\mathrm{y}} \mathrm{l}_{\mathrm{o}}^{*}\left(\frac{\sigma_{\mathrm{f}}}{\sigma_{\mathrm{y}}}\right)^{\mathrm{n}+1}
$$

where $I_{n}$ and $f(n)$ are tabulated for HRR singularities [11]; $\alpha, n, \sigma_{\mathrm{y}}$, and $\varepsilon_{\mathrm{y}}$ are defined from equation (7). $\sigma_{\mathrm{f}}$ is the cleavage stress and $\mathrm{l}_{\mathrm{o}}{ }^{*}$ is a critical microstructural distance. Equation (8) assumes that elastic strains are negligible. From the HRR solution [11,12], for the plane strain case, the plastic strain at the critical microstructural distance is ten times the elastic strain whereas at half this distance the plastic strain is thirty times larger than the elastic component.

Klepaczko $[2,13]$ discusses the rate dependence of material properties for structural steels. If we assume that all material properties are rate independent apart from $\sigma_{\mathrm{y}}$ then $(8)$ reduces to :-

$$
\mathrm{J}_{\mathrm{Ic}}=\text { Constant. } \sigma_{\mathrm{y}}^{2} \cdot\left(\frac{\sigma_{\mathrm{f}}}{\sigma_{\mathrm{y}}}\right)^{\mathrm{n}+1}
$$

The strain rate in the vicinity of the crack changes markedly with distance from the crack tip. However an average crack tip strain rate can be related to the uniaxial strain rate by [12]:-

$$
\dot{\varepsilon}=0.00024 \frac{\dot{J}}{\mathrm{~J}}
$$

Hence equations (10) and (6) can be used to quantify the average dynamic values of yield stress to be used in (9).

A similar analysis can be used for upper shelf behaviour [2]. In this case the crack singularity is lost, the crack tip blunts and fracture is controlled by a critical strain, $\varepsilon_{\mathrm{f}}$ :-

$$
\mathrm{J}_{\mathrm{Ic}}=\mathrm{B}_{\mathbf{u}} \varepsilon_{\mathrm{f}} \mathrm{l}_{\mathbf{f}}^{*} \sigma_{\mathrm{y}}
$$

where $B_{\mathfrak{u}}$ (a material property) and $l_{f}^{*}$ are rate independent. The only influence on the rate dependence of $\mathrm{J}_{\text {Ic }}$ are due to yield stress and fracture strain. Klepaczko [13] has stated that fracture strain is approximately proportional to $1 / \mathrm{n}[14]$ and as in these tests $n$ is approximately rate independent then $\varepsilon_{\mathrm{f}}$ should also be rate independent. It is also assumed that equation (10) is approximately correct even though the crack tip has blunted. 


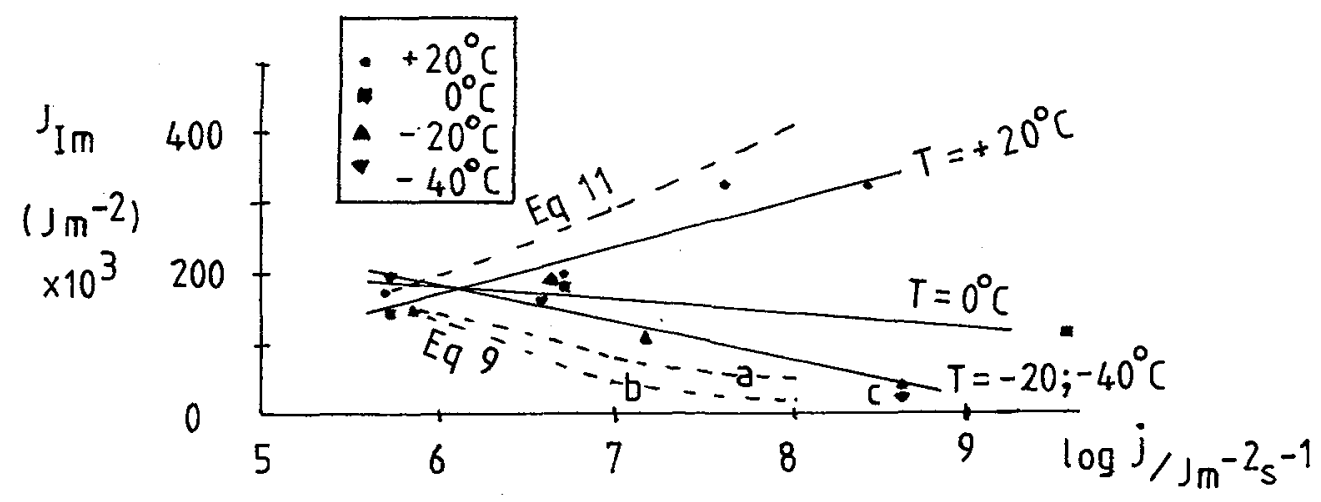

Figure 4: $\mathrm{J}_{\mathrm{Im}}$ versus $\dot{\mathrm{J}}$ for Charpy and CT specimens (10 mm thick) for different temperatures. Annotation ' $C$ ' denotes a Charpy test. ( ' $a$ ' denotes workhardening index, $n,=8$; ' $b$ ' for $n=16$ )

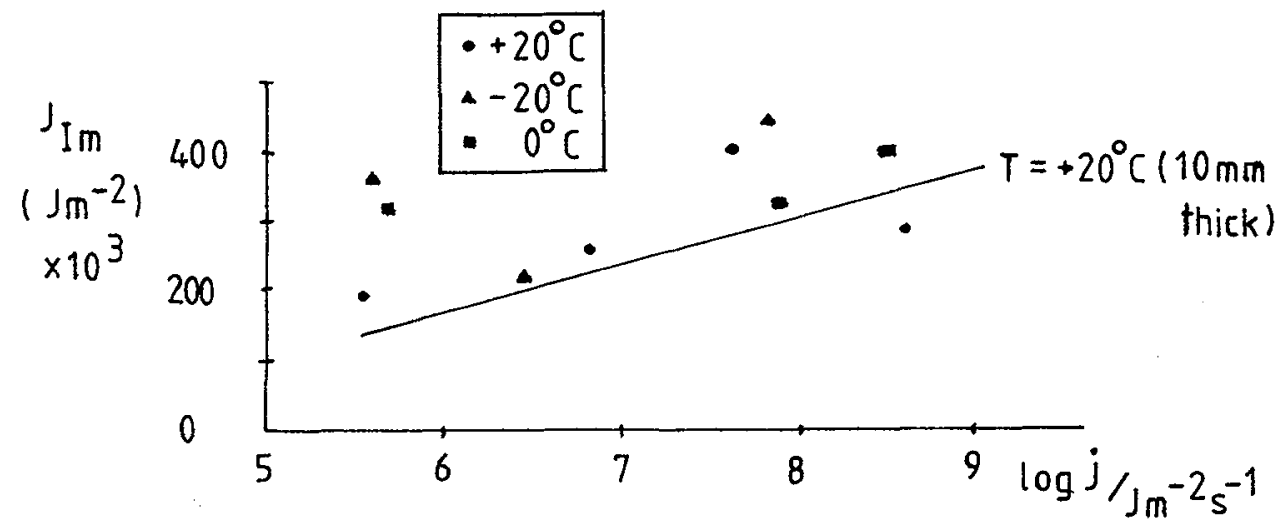

Figure $5: \mathrm{J}_{\mathrm{Im}}$ versus $\dot{\mathrm{J}}$ for CT specimens (5mm thick) for different temperatures.

\section{COMPARISON OF EXPERIMENTAL DATA AND THEORETICAL MODELS}

Figure 4 compares experimental data with calculations using the theoretical models described above. The material constants were defined using the experimental data point at the lowest strain rate $(\dot{J}$ $=10^{6} \mathrm{Jm}^{-2} \mathrm{~s}^{-1}$ in figure 4) and so we are here looking at the trends due to strain rate. In the case of cleavage fracture, the theoretical model underpredicts the toughness at higher rates. This could be due to either the assessment of workhardening or to the assumption of plane strain conditions. Predicted values of $\mathbf{J}_{\mathrm{Ic}}$ are sensitive to workhardening values, $n$. A halving of $n$ from 16 to 8 gives a fourfold increase in fracture toughness. The conditions of plane strain may also change with temperature and strain rate. For the higher ductility cases the fracture process may well become three dimensional.

In the case of strain dominated fracture the agreement is slightly better. The main assumption here is the rate independence of critical strain. Campbell [14] has shown that fracture strain is rate dependent for tensile specimens, however the effect should reduce for the higher constraint and hence smaller strains met at a crack tip.

The effect of temperature on material flow has been included in crack tip models [2], however this has not been discussed here given the approximate nature of strain rate modelling. 


\section{CONCLUSIONS}

Conclusions from the paper are that derived $\mathrm{J}_{\operatorname{Im}}(\mathbf{J}, T)$ data are consistent with results found in the literature [1] viz. reduction in fracture toughness with strain rate for stress controlled fracture and an increase in fracture toughness with strain rate for strain controlled fracture. The bases for these trends are accounted for by simple models given in the literature [2] and these models show that it is the rate dependence in yield stress which has the greatest influence on the variation of fracture toughness with strain rate.

The Hopkinson Pressure Bar loaded Instrumented Charpy Test is most applicable for the high strain rate - low temperature tests whereas the CTS test is most applicable to the lower rates and higher temperatures, where large scale yielding occurs.

The J integral approach gives consistent data for the large scale yielding case, and the measurement of $\mathrm{J}$ at maximum load gives good data for the large range of strain rate and temperature studied.

The simple crack tip models discussed here give insight into the effects of various experimental conditions on resultant fracture toughness. However the models are inaccurate for predictive modelling given the approximate nature of the assessment of the strain rate at the crack tip. To improve accuracy finite element modelling of the crack tip is required and once this is achieved then temperature effects could be included in the material models.

\section{ACKNOWLEDGEMENTS}

In memory of Dr Sara McParland who died of cancer at the age of 32. The research was sponsored by the Health and Safety Executive under contract 2163/R31.08. The facilities of the Impact Research Centre, University of Liverpool were used for the tests.

\section{REFERENCES}

[1] Krabiell A. and Dahl W. " Influence of strain rate and temperature on the tensile and fracture properties of structural steel", Advances in Fracture Research (ICF-5) Volume 1,Cannes,(Pergamon Press,1981),pp393-403.

[2] Klepaczko J.R., Theor. and Appl. Fract.Mech. 1 (1984) 181-191

[3] Mines R.A.W., Int. J. Imp. Eng. 9 (1990) 441-454

[4] Geary W. and Bann P., "Fracture Toughness of 150M12 mining steel to BS2772 under static loading conditions", HSE Section Paper No. R31.07.MQM.01 (1987)

[5] Dutton A.G. and Mines R.A.W.,Int.J. Fract.Mech. 51 (1991) 187-206

[6] MacGillivray $H$. and Cannon D., "Project to develop a standard method of fracture toughness testing at very high loading rates", Rapid Load Fracture Testing, Ed. R.Chona and W Corwin, ASTM STP 1130 (1991)

[7] Jilin Yu and Jones N.,Int. J. Sol. and Struct. 27 (1991) 1113-1137

[8] ASTM, Standard E813 - Test method for J $\mathrm{J}_{\mathrm{IC}}$, a measure of fracture toughness (1981)

[9] BS7448, Proposed standard on fracture mechanics toughness tests, Part III:Method for determination of dynamic fracture tougness testing of metallic materials (1992)

[10] MacGillivray $H$. and Turner C.E., "A comparison of dynamic R curve methods",Mechanical properties of materials at high rates of strain, Ed J.Harding, Oxford 1989 (Institute of Physics 1989) pp.15-22

[11] Kanninen M.F., Popelar C.H., "Advanced Fracture Mechanics"(Oxford University Press, 1985)

[12] Hoff R., Rubin C.A. and Hahn G.T., "High rate deformation in the field of a crack",Material behaviour under high stress and ultrahigh loading rates, Ed. J.Mescall and V.Weiss, (Plenum Press, 1983) pp.223-240

[13] Klepaczko J.R., "Initiation of fracture at different loading rates - an attempt of modelling based on dynamic plasticity”, DYMAT,Paris 1985 (Les Editions de Physique,1985) pp.C5245 - C5250

[14] Campbell J., J. Mech. Phys. Sol. 15 (1967) 359-370 